\title{
The polarities of psychological well being and their response to treatment
}

\author{
Las polaridades del bienestar psicológico y su respuesta al tratamiento
}

\author{
Chiara- Ruini \\ Giovanni A.Fava \\ Department of Psychology, University of Bologna, Italy
}

(Rec:17 de diciembre de 2012 / Acep: 06 de enero de 2013)

\begin{abstract}
An increasing number of investigations in the positive psychology area has suggested the benefits of improving well-being and positivity. However, observations from clinical domains raised some concerns on the effectiveness and utility of such interventions, because excessively elevated levels in positive domains could become detrimental and impede flourishing. The aim of this article is to describe these polarities in well-being and to suggest specific therapeutic strategies to promote flourishing and resilience. Well-being therapy (WBT) is a psychotherapeutic technique based on Ryff's conceptual model, that has been developed and tested in a number of randomized controlled trials. The differential technical characteristics and indications of WBT are described, with special reference to the promotion of an individualized and balanced path to achieve optimal human functioning, avoiding the polarities in positive psychological dimensions. Key words: well-being therapy, positive psychology, positive interventions, psychological well-being; depression, anxiety, recovery
\end{abstract}

\section{Resumen}

Un número creciente de investigaciones en el área de la Psicología positiva sugiere que incrementar el bienestar y la positividad conlleva beneficios. Sin embargo, observaciones del ámbito clínico han suscitado algunas cautelas sobre la efectividad y utilidad de dichas intervenciones ya que niveles excesivamente elevados en los dominios positivos pudieran ser perjudiciales e impide el florecimiento. El objetivo de este artículo es describir estas polaridades en el bienestar y sugerir estrategias terapéuticas para promover el florecimiento y la resiliencia. La terapia del bienestar (TB) es una técnica de psicoterapia, basada en el modelo conceptual de Ryff, que ha sido desarrollada y sometida a prueba en una serie de ensayos clínicos aleatorizados. Se describen las características técnicas diferenciales y las indicaciones de la TB, con especial referencia a la promoción de una vía individualizada y equilibrada para conseguir un funcionamiento humano óptimo, evitando las polaridades en las dimensiones psicológicas positivas.

Palabras clave: terapia del bienestar, Psicología positiva, intervenciones positivas, bienestar psicológico, depresión, ansiedad, recuperación. 


\section{Introduction}

In recent years the growth of positive psychology research has paralleled the increasing interest in concepts such as psychological well-being, quality of life, and optimal human functioning (Cloninger, 2006; Gillham \& Seligman, 1999; Linley, Joseph, Harrington, \& Wood, 2006). This has led to a growing number of investigations on positive emotions (Fredrikson, \& Joiner, 2002), subjective wellbeing (Diener, 2000; Diener Suh, Lucas, \& Smith, 1999), human strengths (Peterson \& Seligman, 2004) and other positive personality characteristics such as compassion, hope, and altruism (Park, Peterson, \& Seligman, 2004). These are as specific ingredients in "positive interventions" (Magayar-Moe, 2009; Rashid, 2009; Seligman, Steen, Park, \& Peterson, 2005; Sin \& Lyubomirsky, 2009) such as the positive psychotherapy (Seligman, Rashid, Parks, 2006); wisdom psychotherapy (Linden, Baumann, Lieberei, Lorenz, \& Rotter, 2011); gratitude interventions (Wood, Maltby, Gillett, Linley, \& Joseph, 2008); positive coaching (Biswas-Diener, 2009; 2010); strengths based approaches (Biswas-Diener, Kashdan, \& Minhas, 2011; Govindji, \& Linley, 2007; Linley \& Burns, 2010); hope therapy (Geraghty, Wood, \& Hyland, 2010; Snyder et al., 2000); and forgiveness therapy (Lamb, 2005).

However, these ideas are not new in clinical psychology: as early as in 1954, Parloff, Kelman \& Frank suggested that the goals of psychotherapy were increased personal comfort and effectiveness, and humanistic psychology suggested concepts such as self-realization and self-actualization as final therapeutic goals (Maslow, 1968; Rogers, 1961). For a long time these latter achievements were viewed only as by-products of the reduction of symptoms or as a luxury that clinical investigators could not afford.

This probably is due to the fact that, historically, mental health research has been dramatically weighted on the side of psychological dysfunction, and health was equated with the absence of illness, rather than the presence of wellness (Ryff \& Singer, 1996). Ryff and Singer (1996) suggested that the absence of well-being creates conditions of vulnerability to possible future adversities and that the route to enduring recovery lies not exclusively in alleviating the negative, but in engendering the positive. The absence of psychological well-being, thus, has been found to be a risk factor for depression (Wood \& Joseph, 2010). Thunedborg, Black \& Bech (1995) observed that quality of life measurement, and not symptomatic ratings, could predict recurrence of depression. An increase in psychological well-being may thus protect against relapse and recurrence (Wood \& Joseph, 2010).On these premises, many of the positive interventions cited above, were addressed at increasing positive emotions, well-being and character's strengths.

Research has indeed suggested the important role of positive affectivity (Fredrikson \& Joiner, 2002) in promoting resilience and growth, but only within a certain level. Extremely high levels of positive emotions can become detrimental and are more connected with mental disorders and impaired functioning (Fredrikson \& Losada, 2005). Larsen and Prizmic (2008) argued that the balance of positive to negative affect (i.e., the positivity ratio) is a key factor in well-being and in defining whether a person flourishes. Several authors (Larsen and Prizmic, 2008; Fredrickson \& Losada, 2005; Schwartz, 1997; Schwartz et al., 2002) suggest that, to maintain an optimal level of emotional well-being and positive mental health, individuals need to experience approximately three times more positive than negative affect. Fredrickson \& Losada (2005) in fact, have found that above this ratio, there is an excessively high positivity which becomes detrimental to functioning.

This insight was confirmed by a recent paper (Grant \& Schwartz, 2011) suggesting that all positive traits, states, and experiences have costs that, at high levels, may begin to outweigh their benefits, creating the nonmonotonicity of an inverted $\mathrm{U}$.

A number of increasing studies, thus, found that 'happier is not always better', particularly under stressful conditions. Excessive positivity in adverse situations, in fact, can signal inappropriate cues to thoughts and action (Fredrickson \& Losada, 2005) or may be accompanied by illusions that are easily shattered by the harsh, hostile reality (Shmotkin, 2005). Even though research suggested that the presence of psychological well-being may be a protective factor (Ryff \& Singer 1996; 1998; Hsiao et al., 2012; Rafanelli \& Ruini, 2012), that could be associated with variations in the biological parameters of individual response to stress and allostatic load (Offidani \& Ruini, 2012; Porcelli et al., 2012; Tomba \& Offidani, 2012), recent findings suggested that specific dimensions of positive functioning, namely autonomy and independence, could to be related to increased level of noradrenaline (Seeman et al., 2002) and seem thus to be associated to an increased stress response.

The aim of this paper is to analyze, by a clinical point of view, the polarities in various dimensions of positive functioning, and to suggest specific treatment options to facilitate human flourishing (Keyes, 2002). 


\section{The polarities in well-being and positive functioning}

Wood and Tarrier (2010) emphasize that characteristics (such as gratitude and autonomy) that are generally regarded as positive, often exist on a continuum. They are neither "negative" or "positive": their impact depends on the specific situation and on the interaction with concurrent distress and other psychological attitudes. For instance, self-efficacy beliefs (Caprara, Alessandri \& Barbaranelli, 2010; Karlsson et al., 2011) and emotional inhibition (Grandi, Sirri, Wise, Tossani, Fava, 2011) may affect the expression of positive orientation.

A comprehensive model of positive functioning and flourishing was provided by Ryff (1989). It encompasses six dimensions of eudaimonic well-being: autonomy, environmental mastery, personal growth, purpose in life, selfacceptance and positive interpersonal relationships. Indeed, these dimensions are often impaired in patients with affective disorders (Fava et al., 1998a; Fava et al., 2001; Rafanelli et al., 2000). However, a variety of clinical situations has provided data and indicators that psychological distress or even psychopathology may arise when these dimensions are too elevated (Ruini \& Fava, 2012).

The autonomy construct refers to independence, selfdetermination and the ability to resist social pressure to think or act in certain ways. This dimension is often impaired in patients with social phobia, or other anxiety disorders. On the other hand, an unbalanced high autonomy can become detrimental for social/interpersonal functioning (Seeman et al., 2002). Some patients complain they are not able to get along with other people, or work in team, or maintain intimate relationships, because they are constantly fighting for their opinions and independence.

Environmental Mastery consists of taking advantage of environmental opportunities, participating in work and familial activities and possessing a sense of competence in managing everyday activities. This is the most frequent impairment that emerges in patients with affective disorders. On the other hand, sometimes patients may require help because they are unable to enjoy and savour daily life, as they are too engaged in work or family activities. Their abilities of planning and solving problems may lead others to constantly ask for their help, with the resulting feeling of being exploited and overwhelmed by requests. These extremely high levels of environmental mastery thus become a source of stress and allostatic load to the individual. Environmental mastery can be considered a key mediator or moderator of stressful life experiences (Fava et al., 2010).
The dimension of Personal Growth consists of being open to new experiences, being capable of facing challenges and tasks at different periods of life and considering the self as growing and expanding over time. A basic impairment that emerges in patients is the inability to identify the progress that has been made toward goal achievement and the similarities between events and situations that were handled successfully in the past and those that are about to come (transfer of experiences). On the other hand people with levels of personal growth that are too high tend to forget on do not give enough emphasis to past experiences because they are exclusively future-oriented. Negative or traumatic experiences could particularly be under-estimated, as a sort of extreme defense mechanism (denial), i.e., "I just need to get over this situation and go on with my life) (Held, 2002; Norem \& Chang, 2002). Dysfunctional high personal growth is similar to a cognitive benign illusion, or wishful thinking, which hinders the integration of past (negative) experiences and their related learning process.

Positive Relations with Others emphasizes the importance of possessing warm and trusting relationships with others, being capable of strong empathy, affection and intimacy. There is a large body of literature (Uchino, Cacioppo \& Kiecolt-Glaser, 1996) on the buffering effects of social integration, social network properties, and perceived support. On the other hand, little research has been conducted on the possible negative consequences of an exaggerated social functioning. Characteristics such as empathy, altruism and generosity are usually considered universally positive. However, in clinical practice, patients often report sense of guilt for not being able to help someone, or to forgive an offence. An individual with a strong pro-social attitude can sacrifice his/her needs and well-being for those of others, and this in the long time becomes detrimental and sometimes disappointing. This individual can also become over-concerned and overwhelmed by others' problems and distress and be at risk for burn-out syndrome.

A person who has purpose in life has goals, intentions, and a sense of direction which contributes to the feeling that life is meaningful. Patients may perceive a lack of sense of direction and may devalue their function in life. This particularly occurs when environmental mastery and sense of personal growth are impaired. On the other hand, many other conditions worthy of clinical attention may arise from inappropriately high levels of purpose in life. First of all individuals with a strong determination in realizing one (or more) life goal(s) could dedicate themselves fully to their activity, thereby allowing them to persist, even in 
the face of obstacles, and eventually to reach excellence. This again could have a cost in terms of allostatic load and stress. Further, while this passion may ensure dedication toward the activity and, eventually, a better performance, it may also be associated with distress, such as damaged relationships, failed commitments and conflicts with other activities in the person's life (Vallerand et al. 2007). The individual engagement for a certain goal could thus become a form of psychological inflexibility (Kashdan \& Rotenberg, 2010) which is more connected with psychopathology, than well-being. Some individuals, in fact, remains attached to their goals even when these seem to be unattainable, and keep believing that they would be happy pending the achievement of these goals. These mechanisms are associated with hopelessness (MacLeod \& Conway, 2007; Hadley $\&$ Mac Leod, 2010) and parasuicidal behaviors (Vincent, Boddana, \& MacLeod, 2004). Further, this confirms the idea that hope, another future-oriented positive emotion, can become paralyzing and hampers facing and accepting negativity and failures (Bohart, 2002, Geraghty, Wood \& Hyland, 2010).

Lastly, the dimension of Self-Acceptance consists of possessing a positive attitude toward the self, recognizing various parts of oneself, such as one's good and bad qualities, feeling self-confident and accepting one's past life and all its positive and negative experiences (Ryff, 1989; Ryff \& Singer, 1996). Patients with affective disorder may maintain unrealistically high standards and expectations, driven by perfectionistic attitudes, that reflect lack of self-acceptance As a result, any instance of well-being is neutralized by a chronic dissatisfaction with oneself. On the other hand, an inflated self-esteem may be a source of distress and clash with reality, as has been found to be the case in cyclothymia and bipolar disorder (Garland et al., 2010; Fava, Rafanelli, Tomba, Guidi \& Grandi, 2011).

These dimensions are strictly connected with other elements of positive functioning, such as gratitude, altruism, forgiveness in the interpersonal domain, self-esteem, self-determination and motivation in the personal domain, hope, wisdom benefit find and optimism in the cognitive domain. The polarities described in the previous pages, thus, could be applied also to these related concepts. They are indeed interrelated and, taken together, they constitute a frame of reference that can be highly individualized (Ryff, 2008). It implies a multiple pathway approach, the idea that there is no single right way to be well and that people have different combinations of strengths and vulnerabilities. As a result, positive interventions should be more articulated than simply increasing positivity, but should take into consideration individual's specific needs and complexities. (Fava et al. 2001; Rafanelli et al., 2000).

\section{The balanced pathway to positive functioning.}

Ryff and Singer (2008) emphasize Aristotele's admonishment to seek "that which is intermediate", avoiding excess and extremes. The pursuit of well-being may in fact be so solipsistic and individualistic to leave no room for human connection and the social good; or it could be so focused on responsibilities and duties outside the self that personal talents and capacities are neither recognized or developed (Ryff \& Singer, 2008). Other body of literature from the philosophic tradition provided similar definitions of harmony, as in the Stoics' ideal of evenness of judgment and detachment, in Plato's description of the just man which relies on the balance between reason, spirit and appetites - and in Epicure's concept of ataraxia - freedom from worries or anxiety through the ability of maintaining balance and serenity in both enjoyable and challenging times (Chenyang, 2008). Ryff and Singer (2008) as well as Grant \& Schwartz (2011) thus, value the concept of balance, both as a theoretical guide and as an empirical reality that scholars of well-being need to appreciate. In 1991 Garamoni et al. suggested that healthy functioning is characterized by an optimal balance of positive and negative cognitions or affects, and that psychopathology is marked by deviations from the optimal balance.

Consequently, the aim of any positive intervention, should be the promotion of an optimal-balanced functioning between the various dimensions of positive functioning described above, in order to facilitate individual flourishing (Keyes, 2002). This means that sometimes patients should be encouraged to decrease their level of positive functioning in certain domains of psychological well-being that can become inappropriate in certain situations. Without this clinical framework, the risk is to lead patients at having too high levels of self-confidence, with unrealistic expectations that may become dysfunctional and/or stressful to individuals. Patients could present, in fact, an inappropriate attitude toward certain dimensions of well-being (too low or too high levels) that hampers self-awareness of personal assets and limitations.

A specific psychotherapeutic strategy based on Ryff's model of psychological well-being - WBT- has been applied to a variety of clinical situations (Fava, 1999; Fava \& Ruini, 2003) . It has provided data and indicators that are consistent with its role in achieving a balanced and individualized 
path to optimal functioning, avoiding polarities in positive psychological dimensions (Ruini \& Fava, 2012)

\section{The structure and clinical framework of well-being- therapy}

Well-being therapy (WBT) is a short-term psychotherapeutic strategy, that extends over 8-12 sessions, which may take place every week or every other week. The duration of each session may range from 30 to 50 minutes. It is a technique which emphasizes self-observation (Emmelkamp, 1974), with the use of a structured diary. The goal of the therapist is to lead the patient from an impaired level to an optimal level in the six dimensions of psychological wellbeing. This means that patients are not simply encouraged to pursue the highest possible levels in psychological wellbeing in all dimensions, but to obtain a balanced functioning. This optimal-balanced well-being could be different from patient to patient, according to factors, such as personality traits, social roles and cultural and social contexts (Ryff, 2008). For example, a patient with an initial diagnosis of social phobia, and with low levels of extraversion, could improve his/her interpersonal relationships, as well as his/ her capacity to voice out his/her opinions and increase autonomy, but it is clinically unrealistic (and probably detrimental) to expect that this patient could transform into an extraverted, friendly and totally independent person. If it happened, probably the patient would pay a high cost in term of stress and allostatic load to maintain these high interpersonal standards.

This clinically modified version of Ryff's (1989) model of eudaimonic well-being is progressively introduced to patients in the WBT session progression.

Well-being therapy has been employed in several clinical studies:

\section{Residual Phase of Affective Disorders.}

The effectiveness of well-being therapy in the residual phase of affective disorders was first tested in a small controlled investigation (Fava, Rafanelli, Cazzaro, Conti \& Grandi, 1998a). Twenty patients with affective disorders (major depression, panic disorder with agoraphobia, social phobia, generalized anxiety disorder, obsessive compulsive disorder) who had been successfully treated by behavioral (anxiety disorders) or pharmacological (mood disorders) methods, were randomly assigned to either a well-being therapy or cognitive behavioral treatment of residual symptoms. Both well-being and cognitive behavioral therapies were associated with a significant reduction of residual symptoms, as measured by the Clinical Interview for Depression (CID) (Guidi, Fava, Bech \& Paykel, 2011) and in PWB well-being. However, when the residual symptoms of the two groups were compared after treatment, a significant advantage of well-being therapy over cognitive behavioral strategies was observed with the CID. Well-being therapy was associated also with a significant increase in PWB well-being, particularly in the Personal Growth scale.

\section{Prevention of Recurrent Depression.}

Well-being therapy was a specific and innovative part of a cognitive behavioral package that was applied to recurrent depression (Fava, Rafanelli, Grandi, Conti \& Belluardo, 1998b), defined as the occurrence of 3 or more episodes of unipolar depression, with the immediately preceding episode being no more than 2.5 years before the onset of the current episode. This package also included cognitive behavioral treatment of residual symptoms and lifestyle modification. Forty patients with recurrent major depression, who had been successfully treated with antidepressant drugs, were randomly assigned to either this cognitive behavioral package including well-being therapy or clinical management. In both groups, antidepressant drugs were tapered and discontinued. The group that received cognitive behavioral therapy-WBT had a significantly lower level of residual symptoms after drug discontinuation in comparison with the clinical management group. Cognitive behavioral therapy-WBT also resulted in a significantly lower relapse rate $(25 \%)$ at a 2 year follow-up than did clinical management (80\%). At a 6 year follow-up (Fava et al., 2004) the relapse rate was $40 \%$ in the former group and $90 \%$ in the latter.

\section{Loss of Clinical Effect during drug treatment}

The return of depressive symptoms during maintenance antidepressant treatment is a common and vexing clinical phenomenon (Fava \& Offidani, 2011). Ten patients with recurrent depression who relapsed while taking antidepressant drugs were randomly assigned to dose increase or to a sequential combination of cognitive-behavior and well-being therapy (Fava, Ruini, Rafanelli \& Grandi, 2002). Four out of five patients responded to a larger dose, but all relapsed again on that dose by 1 year follow-up. Four out of the 5 patients responded to psychotherapy and only one relapsed. The data suggest that application of well-being therapy may counteract loss of clinical effect during longterm antidepressant treatment. 


\section{Treatment of Generalized Anxiety Disorder}

Well-Being Therapy has been applied for the treatment of generalized anxiety disorder (Fava et al., 2005). Twenty patients with DSM-IV GAD were randomly assigned to 8 sessions of cognitive behavioral therapy (CBT) or the sequential administration of 4 sessions of CBT followed by 4 sessions of well-being therapy (WBT). Both treatments were associated with a significant reduction of anxiety. However, significant advantages of the WBT-CBT sequential combination over CBT were observed, both in terms of symptom reduction and psychological well-being improvement. These preliminary results suggest the feasibility and clinical advantages of adding WBT to the treatment of GAD. A possible explanation to these findings is that self-monitoring of episodes of well-being may lead to a more comprehensive identification of automatic thoughts than that entailed by the customary monitoring of episodes of distress in cognitive therapy (Beck \& Emery, 1985), and may thus result in a more effective cognitive restructuring. These results lend support to a sequential use of treatment components for achieving a more sustained recovery.

\section{Post-Traumatic stress disorder}

The use of WBT for the treatment of traumatized patients has not been tested in controlled investigations, yet. However, two cases were reported (Belaise, Fava \& Marks, 2005) in which patients improved with WBT, even though their central trauma was discussed only in the initial history-taking session. The findings from these two cases should of course be interpreted with caution (the patients may have remitted spontaneously), but are of interest because they indicate an alternative route to overcoming trauma and developing resilience and warrant further investigation (Fava \& Tomba, 2009).

\section{Cyclothymic disorder}

Cyclothymia involves mild or moderate fluctuations of mood, thought, and behaviour in what would now be considered 'subsyndromal' mild hypomanic or depressive-dysthymic directions without meeting formal diagnostic criteria for either major depressive disorder or mania (Baldessarini, Vazquez \& Tondo, 2011). It may entail potential negative physical (Fiedorowicz, Coryell, Rice, Warren, \& Haynes, 2012) and cognitive (Fuentes-Durá et al., 2012) implications. Well-being therapy was recently applied in sequential combination with cognitive behavioral therapy (CBT) for the treatment of cyclothymic disorder (Fava, Rafanelli,
Tomba, Guidi \& Grandi, 2011). Sixty-two patients with DSM-IV cyclothymic disorder were randomly assigned to CBT/WBT $(n=31)$ or clinical management $(\mathrm{CM})(\mathrm{n}=31)$. Both CBT/WBT and CM consisted of ten 45-min sessions every other week. An independent blind evaluator assessed the patients before treatment, after therapy, and at 1- and 2-year follow-ups. The outcomes included total score of the change version of the Clinical Interview for Depression, and the Mania Scale. At post treatment, significant differences were found on all outcome measures, with greater improvements after treatment in the CBT/WBT group compared to the CM group. Particularly, patients' scores in the Mania scales were decreased after WBT. Thus, excessive positivity was reduced to a more balanced functional level. Therapeutic gains were maintained at 1- and 2-year follow-ups. The results of this investigation suggest that a sequential combination of CBT and WBT, which addresses both polarities of mood swings and comorbid anxiety, was found to yield significant and persistent benefits in cyclothymic disorder. The findings support the hypothesis that cyclothymic disorder is a treatable condition, and that the 5-month psychotherapy intervention offered showed substantial benefits that persisted for at least 2 years. In this investigation WBT was found to be particularly effective in controlling the hypomanic component of cyclothymia. For instance, the presence of positive arbitrary inferences that escape critical appraisal may lead to inflated environmental mastery that clashes with reality and leads to disappointments and demoralization and can only be fully assessed if also the instances of perceived well-being are monitored.

\section{Conclusions}

WBT was originally developed as a strategy for promoting psychological well-being which was still impaired after standard pharmacological or psychotherapeutic treatments in clinical populations. It was based on the assumption that these impairments may vary from one illness to another, from patient to patient and even from one episode to another of the same illness in the same patient. These impairments represent a vulnerability factor for adversities and relapses (Fava \& Tomba, 2009; Ryff \& Singer, 1996; Wood \& Joseph, 2010). WBT, thus, can be considered a therapeutic positive intervention developed in clinical psychology, which takes into consideration both well-being and distress in predicting patients' clinical outcomes (Rafanelli \& Ruini, 2012).

In the present paper we have enlarged the conceptual framework of WBT to address the emerging issues related 
to the balance of dimensions underlying psychological wellbeing (Ryff \& Singer, 2008, Grant \& Schwartz, 2011). Not only impairments of psychological well-being may vary from one disorder to another (Rafanelli et al., 2000; Fava et al., 2001; Wood \& Joseph, 2010; Cosci et al., 2011), but also from one individual to another within the same illness. Further, recent work on cyclothymic disorder (Fava et al. 2011) has indicated that excessive polarities in autonomy, environmental mastery, positive interpersonal relationships, self-acceptance, purpose in life and personal growth may clash with reality and lead to mood swings. This flexibility and diverse applicability of WBT is in line with the proposed positive clinical psychology approach, which calls for a number of different interventions to be selected based on individual specific needs (Fava, Ruini, Tomba \& Wise, 2012; Tomba \& Bech, 2012; Wood \& Tarrier, 2010).

We suggest that the pathway to optimal, balanced wellbeing can be obtained with highly individualized strategies. In some cases some psychological dimensions need reinforcement and growth. In other cases an excessive or distorted levels of certain dimensions needs to be adjusted because they may become dysfunctional and impede flourishing. Individuals may be helped to move up form impaired low levels to optimal, but also to move down from inappropriately high- to optimal-balanced levels. This could be achieved using specific behavioural homeworks, assignment of pleasurable activities, but also cognitive restructuring aimed at reaching a more balanced positive functioning in these dimensions.

George Engel (1960) defined etiological factors as "factors which either place a burden on or limit the capacity of systems concerned with growth, development or adaptation" (p.473). Well-being therapy attempts to address these etiological factors and to lead patients to an increased level of recovery and adaptive positive functioning.

\section{References}

Baldessarini, R. J., Vázquez, G., \& Tondo, L. (2011). Treatment of cyclothymic disorder: Commentary. Psychotherapy and Psychosomatics, 80, 131-135.

Beck, A. T., \& Emery, G. (1985). Anxiety disorder and Phobia. New York: Basic Book.

Belaise, C., Fava, G. A., \& Marks, I. M. (2005). Alternatives to debriefing and modifications to cognitive behavior therapy for posttraumatic stress disorder. Psychotherapy and Psychosomatics, 74, 212-217.

Biswas-Diener, R. (2009). Personal coaching as a positive intervention. Journal of Clinical Psychology, 65, 544-553.

Biswas-Diener, R. (2010). A positive way of addressing negatives: Using strengths-based interventions in coaching and therapy. In G. W. Burns (Ed), Happiness, healing and enhancement: your casebook collection for applying positive psychology in therapy (pp. 291-302). Hoboken, New Jersey: Wiley.
Biswas-Diener, R., Kashdan, T. B., \& Minhas, G. (2011). A dynamic approach to psychological strength development and intervention. Journal of Positive Psychology, 6, 106-118.

Bohart, A. C. (2002). Focusing on the positive, focusing on the negative: implications for psychotherapy. Journal of Clinical Psychology, 58, 1037-1043.

Caprara, G. V., Alessandri, G., \& Barbaranelli, C. (2010). Optimal Functioning: contribution of self-efficacy beliefs to positive orientation. Psychotherapy and Psychosomatics, 79, 328-330.

Chenyang, L. (2008). The ideal of harmony in ancient Chinese and Greek philosophy. Dao, 7, 81-98

Cloninger, C. R. (2006). The science of well-being. World Psychiatry, 5, 71-76.

Cosci, F., Pennato, T., Bernini, O., \& Berrocal, C. (2011). Psychological well-being, negative affectivity, and functional impairment in fibromyalgia. Psychotherapy and Psychosomatics, 80, 256-258

Diener, E. (2000). Subjective well-being: the science of happiness, and a proposal for a national index. American Psychologist, 55, 34-43.

Diener, E., Suh, E. M., Lucas, R. E., \& Smith, H. L. (1999). Subjective well-being: three decades of progress. Psychological Bulletin, 125, 276-302.

Emmelkamp, P. M. G. (1974). Self-observation versus flooding in the treatment of agoraphobia. Behaviour Research and Therapy, 12, 229-237.

Engel, G. L. (1960). A unified concept of health and disease. Perspective in Biology and Medicine, 3, 459-483.

Fava, G. A. (1999). Well-being therapy. Psychotherapy and Psychosomatics, 68, 171-178.

Fava, G. A., \& Offidani, E. (2011). The mechanisms of tolerance in antidepressant action. Progress in Neuro-psychopharmacology \& Biological Psychiatry, 35, 1593-602.

Fava, G. A., \& Ruini, C. (2003). Development and characteristics of a well-being enhancing psychotherapeutic strategy: well-being therapy. Journal of Behavior Therapy and Experimental Psychiatry, 34, 45-63.

Fava, G. A., \& Tomba, E. (2009). Increasing psychological well-being and resilience by psychotherapeutic methods. Journal of Personality, 77, 1903-1934.

Fava, G. A., Guidi, J., Semprini, F., Tomba, E., \& Sonino, N. (2010). Clinical assessment of allostatic load and clinimetric criteria. Psychotherapy and Psychosomatics, 79, 280-284.

Fava, G. A., Rafanelli, C., Cazzaro, M., Conti S., \& Grandi, S. (1998a ). Well-being therapy. A novel psychotherapeutic approach for residual symptoms of affective disorders. Psychological Medicine, 28, 475-480.

Fava, G. A., Rafanelli, C., Grandi, S., Conti, S., \& Belluardo, P. (1998b). Prevention of recurrent depression with cognitive behavioral therapy. Archives of General Psychiatry, 55, 816-820.

Fava, G. A., Rafanelli, C., Ottolini, F., Ruini, C., Cazzaro, M., \& Grandi, S. (2001). Psychological well-being and residual symptoms in remitted patients with panic disorder and agoraphobia. Journal of Affective Disorders, 31, 899-905.

Fava, G. A., Rafanelli, C., Tomba, E., Guidi, J., \& Grandi, S. (2011). The sequential combination of cognitive behavioral treatment and Well-being Therapy in cyclothymic disorder. Psychotherapy and Psychosomatics, 80, 136-143.

Fava, G. A., Ruini, C., Rafanelli, C., \& Grandi, S. (2002). Cognitive behavior approach to loss of clinical effect during long-term antidepressant treatment. American Journal of Psychiatry, 159, 2094-2095.

Fava, G. A, Ruini, C., Rafanelli, C., Finos, L., Conti, S., \& Grandi, S. (2004). Six year outcome of cognitive behavior therapy for prevention of recurrent depression. American Journal of Psychiatry, 161, 1872-1876.

Fava, G. A., Ruini, C., Rafanelli, C., Finos, L., Salmaso, L., Mangelli, L., \& Sirigatti, S. (2005). Well-being therapy of generalized anxiety disorder. Psychotherapy and Psychosomatics, 74, 26-30.

Fava, G. A., Ruini, C., Tomba, E., \& Wise, T. N. (2012). The Biopsychosocial Factor. Psychotherapy and Psychosomatics, 81, 1-4.

Fava, G. A., Tomba, E., \& Grandi, S. (2007). The road to recovery from depression. Psychotherapy and Psychosomatics, 76, 260-265. 
Fiedorowicz, J. G., Coryell, W. H., Rice, J. P., Warren, L. L., \& Haynes, W. G. (2012). Vasculopathy related to manic/hypomanic symptom burden and first-generation antipsychotics in a sub-sample from the collaborative depression study. Psychotherapy and Psychosomatics, 81, 235-243

Fredrickson, B. L., \& Joiner, T. (2002). Positive emotions trigger upward spirals toward emotional well-being. Psychological Science, $13,172-175$

Fredrickson, B. L., \& Losada, M. F. (2005). Positive affect and the complex dynamics of human flourishing. American Psychologist, 60, 678-686.

Fuentes-Durá, I., Balanzá-Martínez, V., Ruiz-Ruiz, J. C., Martínez-Arán, A., Girón, M., Solé, B, Sánchez-Moreno, J., Gómez-Beneyto M, Vieta E, ... Tabarés-Seisdedos, R. (2012). Neurocognitive training in patients with bipolar disorders: current status and perspectives. Psychotherapy and Psychosomatics, 81, 250-252

Garamoni, G. L., Reynolds, C. F., Thase, M. E., Frank, E., Berman, S. R., \& Fasiczska A. L. (1991). The balance of positive and negative affects in major depression. Psychiatry Research, 39, 99-108.

Garland, E. L., Fredrickson, B., Kring, A. M., Johnson, D., Meyer, P. S., \& Penn, D. L. (2010). Upward spirals of positive emotions counter downspirals of negativity. Insights from the broaden-and-built theory and affective neurosciense on the treatment of emotion dysfunction and deficits in psychopathology. Clinical Psychology Review, 30, 849-864.

Geraghty, A. W. A., Wood, A. M., \& Hyland, M. E. (2010). Dissociating the facets of hope: Agency and pathways predict dropout from unguided self-help therapy in opposite directions. Journal of Research in Personality, 44, 155-158.

Gillham, J. E., \& Seligman, M. E. P. (1999). Footsteps on the road to a positive psychology. Behaviour Research and Therapy, 37, 163-173.

Govindji, R., \& Linley, P. A. (2007). Strengths use, self-concordance and well-being: Implications for strengths coaching and coaching psychologists. International Coaching Psychology Review, 2, 143-153.

Grandi, S., Sirri, L., Wise, T. N., Tossani, E., \& Fava, G. A. (2011). Kellner's Emotional Inhibition Scale: a clinimetric approach to alexithymia research. Psychotherapy and Psychosomatics, 80, 335-344.

Grant, A. M., \& Schwartz, B. (2011) Too much of a good thing : The challenge and opportunity of the inverted U. Perspectives on Psychological Science, 6, 61-76.

Guidi, J., Fava, G. A., Bech, P., \& Paykel, E. S. (2011). The Clinical Interview for Depression. Psychotherapy and Psychosomatics, 80, 10-27

Hadley, S., \& Macleod, A. K. (2010). Conditional goal-setting, personal goals and hopelessness about the future. Cognition and Emotion, 24, 1191-1198.

Held, B. S. (2002). The tyranny of positive attitude in America: observation and speculation. Journal of Clinical Psychology, 58, 965-992.

Hsiao, FH., Jow, G. M., Kuo, W. H., Chang, K. J., Liu, Y. F., Ho, R. T. H., ... Chen, Y. T. (2012). The effects of psychotherapy on psychological well-being and diurnal cortisol patterns in breast cancer survivors. Psychotherapy and Psychosomatics, 81,173-182

Karlsson, H., Kronström, K., Nabi, H., Oksanen, T., Salo, P., . . . Virtanen, M. (2011). Low level of optimism predicts initiation of psychotherapy for depression: results from the Finnish Public Sector Study. Psychotherapy and Psychosomatics, 80, 238-244.

Kashdan, T. B., \& Rottenberg, J. (2010). Psychological flexibility as a fundamental aspect of health. Clinical Psychology Review, 30, 865-878.

Keyes, C. L. (2002). The mental health continuum: form languishing to flourishing in life. Journal of Health and Social Behavior, 43, 207-222.

Lamb, S. (2005). Forgiveness therapy: The context and conflict. Journal of Theoretical and Philosophical Psychology, 25, 61-80.

Larsen, R. J., \& Prizmic, Z. (2008). Regulation of emotional well-being: Overcoming the hedonic treadmill. In M. Eid \& R . J. Larsen (Eds. ), The science of subjective well-being (pp. 259-289). New York: Guilford.

Linden, M., Baumann, K., Lieberei, B., Lorenz, C., \& Rotter, M. (2011). Treatment of posttraumatic embitterment disorder with cognitive behaviour therapy based on wisdom psychology and hedonia strategies. Psychotherapy and Psychosomatics, 80, 199-205.

Linley, P. A., \& Burns, G. W. (2010). Strengthspotting: Finding and developing client resources in the management of intense anger. In G. W. Burns (Ed), Happiness, Healing and Enhancement: your casebook collection for applying positive psychology in therapy (pp. 3-14). Hoboken, New Jersey: Wiley.

Linley, P. A., Joseph, S., Harrington, S., \& Wood, A. M. (2006). Positive psychology: Past, present, and (possible) future. The Journal of Positive Psychology, 1, 3-16.

MacLeod, A. K., \& Conway, C. (2007). Well-being and the anticipation of future positive experiences: The role of income, social networks and planning ability. Cognition and Emotion, 18, 357-374.

Magayar-Moe, J. (2009). Therapist's guide to positive psychological interventions. New York, NY: Academic Press, Elsevier.

Maslow, A. H. (1968). Toward a psychology of being (2nd Ed. ) New York: Van Nostrand.

Norem, J. K., \& Chang, E. C. (2002) . The positive psychology of negative thinking. Journal of Clinical Psychology, 58, 993-1001.

Offidani, E., \& Ruini, C. (2012). Psychobiological correlates of allostatic overload in a healthy population. Brain Behavior and Immunity, 26, 284-291

Park, N., Peterson, C., \& Seligman, M. E. P. (2004). Strengths of character and well-being. Journal of Social and Clinical Psychology, 23, 603-619.

Parloff, M. B., Kelman, H. C., \& Frank, J. D. (1954). Comfort, effectiveness, and self-awareness as criteria of improvement in psychotherapy. American Journal of Psychiatry, 11, 343-351.

Porcelli, P., Laera, D., Mastrangelo, D., \& Di Masi, A. (2012). Prevalence of allostatic overload syndrome in patients with chronic cardiovascular disease. Psychotherapy and Psychosomatics, 82, 375-377.

Rafanelli, C., Park, S. K., Ruini, C., Ottolini, F., Cazzaro, M. \& Fava, G. A. (2000). Rating well-being and distress. Stress Medicine, 16, 55-61.

Rafanelli, C., \& Ruini, C. (2012). The assessment of psychological well-being in psychosomatic medicine. Advances in Psychosomatic Medicine, 32, 182-202

Rashid, T. (2009). Positive interventions in clinical practice. Journal of Clinical Psychology, 65, 461-466.

Rogers, C. R. (1961). On becoming a person. Boston: Houghton Mifflin.

Ruini, C., \& Fava, G. A. (2012). The role of Well-Being Therapy in achieving a balanced and individualized path to optimal functioning. Clinical Psychology and Psychotherapy, 19, 291-304

Ryff, C. D. (1989). Happiness is everything, or is it? Explorations on the meaning of psychological well-being. Journal of Personality and Social Psychology, 6, 1069-1081.

Ryff, C. D. (2008). Challenges and opportunities at the interface of aging, personality and well-being. In O. P. John, R. W. Robins, \& L. A. Pervin (Eds): Handbook of Personality: theory and research (pp. 399-418). New York, NY, US: the Guilford Press.

Ryff, C. D., \& Singer, B. H. (1996). Psychological well-being: meaning, measurement, and implications for psychotherapy research. Psychotherapy and Psychosomatics, 65, 14-23.

Ryff, C. D., \& Singer, B. H. (1998). The contours of positive human health. Psychological Inquiry, 9, 1-28.

Ryff, C. D., \& Singer, B. H. (2008). Know thyself and become what you are: a eudaimonic approach to psychological well-being. Journal of Happiness Studies, 9, 13-39.

Seeman, T. E., Singer, B. H., Ryff, C. D., Dienberg, Love, G., \& LevyStorms L. (2002). Social relationships, gender, and allostatic load across two age cohorts. Psychosomatic Medicine, 64, 395-406.

Seligman, M. E. P., Rashid, T., \& Parks, A. C. (2006). Positive psychotherapy. American Psychologist, 61, 774-788.

Seligman, M. E., Steen, T. A., Park, N., \& Peterson, C. (2005). Positive psychology progress: Empirical validation of interventions. American Psychologist, 60, 410-421.

Schwartz, R. M. (1997). Consider the simple screw: Cognitive science, quality improvement, and psychotherapy. Journal of Consulting and Clinical Psychology, 65, 970-983.

Schwartz, R. M., Reynolds, C. F., Thase, M. E., Frank, E., Fasiczka, A. L., \& Haaga, D. (2002). Optimal and normal affect balance in psychotherapy of major depression: Evaluation of the balanced states of mind model. Behavioral and Cognitive Psychotherapy, 30, 439-450.

Shmotkin, D. (2005). Happiness in face of adversity: reformulating the dynamic and modular bases of subjective well-being. Review of General Psychology, 9, 291-325. 
Snyder, C. R., Ilardi, S., Michael, S. T., Yamhure, L., \& Sympson, S. (2000). The role of hope in cognitive behavior therapies. Cognitive Therapy and Research, 24, 747-762.

Thunedborg, K., Black, C. H., \& Bech, P. (1995). Beyond the Hamilton depression scores in long-term treatment of manic-melancholic patients: prediction of recurrence of depression by quality of life measurements. Psychotherapy and Psychosomatics, 64, 131-140.

Tomba, E., \& Bech, P. (2012). Clinimetric and clinical psychometrics. Psychotherapy and Psychosomatics, 81, 333-343

Tomba, E., \& Offidani, E. (2012). A clinimetric evaluation of allostatic overload in the general population. Psychotherapy and Psychosomatics, 81, 378-379.

Uchino, B. N., Cacioppo, J. T., \& Kiecolt-Glaser J. V. (1996). The relationship between social support and physiological processes. Psychological Bulletin 119, 488-531.

Vallerand, R. J., Salvy, S. J., Mageau, G. A., Elliot, A. J., Denis, P. L., Grouzet, F. M. E., \& Blanchard, C. (2007). On the role of passion in performance. Journal of Personality, 75, 505-534.
Vincent, P. J., Boddana, P., \& MacLeod, A. K. (2004). Positive life goals and plans in parasuicide. Clinical Psychology and Psychotherapy, 11, 90-99.

Wood, A. M., \& Joseph, S. (2010). The absence of positive psychological (eudemonic) well-being as a risk factor for depression: A ten year cohort study. Journal of Affective Disorders, 122, 213-217.

Wood, A. M., \& Tarrier, N. (2010). Positive clinical psychology: A new vision and strategy for integrated research and practice. Clinical Psychology Review, 30, 819-829.

Wood, A. M. , Maltby, J. , Gillett, R. , Linley, P. A. , \& Joseph, S. (2008). The role of gratitude in the development of social support, stress, and depression: Two longitudinal studies. Journal of Research in Personality, 42, 854-871. 
